\title{
SYNTACTIC TRANSLATION STRATEGIES FOR RETAINING PARALLELISM IN THE ARABIC TRANSLATION OF MOBY DICK
}

\author{
Mohd Nor IKBAL ${ }^{1}$ \\ Universiti Putra Malaysia \\ A2-10-01, Taratak Muhibah 2, Taman Danau Desa, \\ Jalan Klang Lama, 58100, Kuala Lumpur \\ Syed Nurulakla SYED ABDULLAH ${ }^{2}$ \\ Universiti Putra Malaysia \\ Department of foreign languages \\ Faculty of modern languages and communication, \\ University putra Malaysia, 43400 UPM Serdang \\ Selangor Darul Ehsan \\ Omar Osman JABAK ${ }^{3}$ \\ Department of Arts and Education \\ Community College \\ King Saud University \\ ${ }^{1}$ mn_ikbal@yahoo.com* \\ 2syedakla@upm.edu.my \\ 33ojabak@ksu.edu.sa
}

*Corresponding author

Manuscript received 21 July 2016

Manuscript accepted 7 November 2016

\begin{abstract}
The present study examines strategies for translating parallelism and factors in retaining parallelism in the Arabic translation of the novel of "Moby Dick". Analysis is conducted on two sets of data taken from the English novel "Moby Dick" written by Melville in 1851 and its Arabic translation 'Mūbī Dīk' by 'Abbās (1980). This qualitative research is guided by Chesterman's (1997) syntactic strategy model, and contrastive analysis (CA) is also performed. The contrastive analysis is carried out using a coding procedure based on themes and taxonomies in the acquired data constructed by the researchers. The result shows that, based on Chesterman's (1997) model, the translator of the above-mentioned novel employed three strategies, namely, literal translation, clause structure change and transposition to maintain parallelism in the Arabic translation of the English novel.
\end{abstract}


Keywords: parallelism, syntactic strategies, translation strategy, Moby Dick, EnglishArabic translation

\section{Introduction}

It can be argued that the translation process involves translators' efforts to transfer texts along with their linguistic, cultural and rhetorical aspects from one language and culture into another language and culture. In the Arabic translation of the English novel "Moby Dick" which is entitled 'Mūbī Dīk' (1980), there are several rhetorical devices employed by the author which have been transferred by the translator. In this context, the researchers attempt to investigate the translation strategy of parallelism, one of the rhetorical devices used by the author of the source text along with the translator's strategies for retaining parallelism in the target text, i.e. the Arabic translation of "Moby Dick".

According to Quayum and Talif (2000), parallelism is a device of writing in which elements of equal importance are balanced out in similar grammatical constructions. This could be in a sentence, a paragraph, or even a larger unit of composition. As a matter of fact, writers often use this device to emphasise something or add an aesthetic value to their work(s).

In analysing the Arabic translation "Mūbī Dīk" which was published by Mü'assasah Nāșir lïlthaqāfaf in 1980, the researchers focused on the translator's strategy for translating parallelism based on the syntactic model proposed by Chesterman (1997). In fact, translating parallelism, or parallel structures, depends, to a large extent, on the ability of the translator to maintain the author's style and content. When the translator cannot do that, the target text sustains unintentional parallelism loss. Besides, syntactic structures change in the target text as English and Arabic, for example, belong to two different families which have different linguistic systems. When translation is carried out in this language pair, English and Arabic, there are definitely some linguistic changes in the target text. One such change affects parallelism.

With parallelism in mind, the present study examined the strategies which the translator of "Moby Dick" adopted to retain parallelism in his Arabic translation in accordance with Chesterman's (1997) model of syntactic strategies. The researchers also attempted to identify the factors in retaining parallelism by carrying out a contrastive analysis for this purpose.

\section{Literature Review}

\section{Studies on Parallelism}

There have been several studies on the translation of parallelism. To begin with, Jawad (2007) analysed parallelism with anaphora and parallelism with synonymy. The issue was repetition attributed to parallelism which has different functions in different languages and it has its own place in different cultures. Jawad (2007) 
analysed the data by placing the target text (TT) against the source text (ST) in order to determine the repetition frequency in English and to scan the strategies and norms that can be applied while determining certain translation choices. The data analysed came from the three-part autobiography of al-Ayyām (The Days) with their translations by Taha Hussein and the novel Hadīth 'T̄sā ibn Hishām ('Īsā ibn Hishām's Tale) by Muhammad al-Muwaylihi. Jawad (2007) discovered that parallelism fulfilled the rhetorical and cohesive purposes. It was employed either in a series of utterances conveying patterns of transitivity or foregrounding the contrastive image. The purpose of the TT and the function of the ST were very clear as that depended on the translator's choice.

Shamaileh (2011) examined parallelism in political speeches in terms of its role, frequency occurrence and impact on the ST readers. The data were derived from thirty Hashemite political speeches. They consisted of ten speeches in Arabic together with their ten official English translations. The objectives were to examine parallelism frequency, level, patterns and impact as reflected in these speeches, and to see whether the linguistic phenomenon remains intact or whether the English translations compensated for it by using rhetorical features. Shamaileh (2011) applied three kinds of methodological tools to study these three aspects: "critical discourse analysis" (CDA) to measure political discourse and argumentative text typology; "contrastive analysis" to measure parallelism as a stylistic device; and "translation studies" to measure parallelism as a context of original speech. Shamaileh (2011) found that parallelism was an effective rhetorical device as it occurred in Arabic. In contrast, English parallelism was not as common. In terms of the stylistic aspect, Shamaileh (2011) found that Arabic parallelism was a comprehensive device for the Arabic language, and it contains rhetorical, stylistic, persuasive and cohesive devices. On the other hand, English parallelism was different; it tended to use a series of three main elements, namely, pronouns, reminiscence, the use of contrastive pairs, among others.

Mehawesh (2013) examined grammatical parallelism in advertising. His objective was to examine grammatical parallelism in advertisement, particularly English into Arabic. Mehawesh suggested that the study could provide an understanding of the strategies of translating advertisements in two different cultures. The aim of the study was to show the differences between two cultures with two visible distinctive characteristics. A distinct issue in translating grammatical parallelism was particularly a challenging task. The difficulty lies in creating textual semantic units and retaining their forms while maintaining their translation equivalence. The data consisted of several advertisements in English with their Arabic translations. These advertisements were collected from Alrai, Addustour and Alwaseet newspapers over the period between January 2012 and June, 2012. He found that parallelism was maintained in both languages. However, the function was different. In Arabic, parallelism served as a figure of speech, while English parallelism served as a text-structuring device.

An (2010) investigated syntactic and pragmatic parallelism in political speeches. His aim was to analyse some syntactic features and explore some pragmatic features of parallelism both in English and Vietnamese in order to get insights into parallelism in political speech. He employed a descriptive, qualitative 
and contrastive analysis by which the data were analysed in terms of syntax and pragmatics. He found that parallelism in both languages was largely employed in order to achieve the aims of the politicians' speech, to focus on a certain issue, to have firm impressions on listeners and to convince the audience of the speaker's point of view or solution and then perform a certain action.

Al-Subhi (2009) investigated parallelism in poetry. His main objective was to explore parallelism as a significant stylistic device used in some selected children's poems. The sample was selected from 25 Eloise Greenfield's children poetry which includes examples of parallelism. The analysis was carried out stylistically. The analysis came up with different parallelism patterns at different parallelism linguistic levels. The sample was discussed at four micro linguistic levels, phonology, morphology, syntax and semantics. Finally, Al-Subhi (2009) found parallelism as a foreground regularity on phonological, grammatical and semantic levels.

Zhao (2012) examined parallelism in a novel. His aim was to study parallelism density and variety in Virginia Woolf's novel To the Lighthouse by comparing Woolf's novel to other modernist novels and discussing particular lexical and syntactic features which build Woolf's parallelism. Zhao (2012) found that the rhetoric of opposition determined Woolf's lexical choice of certain paralleled parties.

\section{Studies on Chesterman's Syntactic Strategies}

There is a substantial amount of research on Chesterman's (1997) syntactic strategies. These strategies have been employed in English-Indonesian, EnglishBrazilian Portuguese, Japanese-English, Finnish-Chinese and English-Arabic translation. There are some studies adopting Chesterman's (1997) translation strategies comprehensively i.e. syntactic, pragmatic and semantic and some other studies following only Chesterman's (1997) syntactic strategies.

De Oliveira Branco (2012) studied Chesterman's (1997) translation strategies in investigating translation methodological procedures. The researcher selected a compilation of online English newspapers such as, Reuters, BBC, The New York Times and UOL Jornais. All the news was on conflicts in the Middle East translated into Brazilian Portuguese. He analysed three major translation strategies: syntactic, semantic and pragmatic, adopted from Chesterman (1997), to see how translation is practised in online news reporting. He found that literal translation (syntactic strategies) was extensively used followed by synonymy (semantic strategies), information change (pragmatic strategy) and explicitness change (pragmatic strategy).

Mizher (2016) investigated Chesterman's (1997) syntactic strategies adopted by EFL students in translating English passive voice into Arabic. The participants were Jordanian students at public and private universities taking a general translation course. The researcher gave the students a translation test consisting of five sentences containing 181 words. The sentences were taken from the BBC English website and several Jordanian online English newspapers. The participants were allowed to use dictionaries and were provided with the keywords to help them seek the equivalent word in Arabic. In this way, the participants would 
pay attention to syntactic structures. Mizher (2016) found that the participants employed literal translation, transposition, clause structure change and sentence structure change as strategies to help them translate effectively.

\section{Methodology}

This qualitative study adopted the syntactic strategy model proposed by Chesterman (1997) as its basic theoretical framework. The empirical comparison will be drawn between ST-TT parallelism. Every ST parallelism was compared to its Arabic translation or counterpart to justify the strategy used by the translator in retaining parallelism in accordance with Chesterman's (1997) model.

In this research, the researchers focused only on "Moby Dick" and its Arabic translation. In addition, the collected data were only limited to parallelism which was readily available in "Moby Dick" and its Arabic translation. Rhetorical devices other than parallelism were not the subject of this research. In order to get a comprehensive overview, parallelism was examined in all chapters of "Moby Dick" and its translation - Mūbī Dỉk. The researchers held the discussions in accordance with the translation discipline only.

A contrastive analysis was applied to two sets of data taken from "Moby Dick" by Herman Melville in 1851 as the source text (ST) and Mūbī Dīk, its Arabic translation by Dr. Ihsãn 'Abbãs (1980) published by Muassasah Naser As-Saqafah as the target text (TT). A total of 50 translation cases were collected, but only eight cases were presented and discussed in this paper to limit the scope of the paper. After identifying parallelism in the ST and the $\mathrm{TT}$, the data related to parallelism from both texts were collected. The contrastive analysis was used to identify the patterns of syntactic strategies employed by the translator in retaining parallelism in the TT. The identifiable patterns were obtained according to the syntactic structure of English and Arabic sentences.

The analysis was carried out based on the open-ended coding scheme taken directly from Chesterman (1997). Table 1 illustrates the categories along with their codes.

Table 1

Coding scheme in accordance with Chesterman's syntactic strategies

\begin{tabular}{cc}
\hline Categories & Codes \\
\hline Literal translation & -Similar to ST \\
& -maximally close to ST \\
\hline Loan/Calque & -borrowed from ST \\
\hline Transposition & -noun to verb \\
& -adjective to adverb \\
\hline Unit shift & -morphemes to words \\
& -phrases to clauses \\
\hline Phrase structure change & -phrase structure change \\
\hline Clause structure change & -SVO to VSO \\
\hline Sentence group change & -sentence group change \\
\hline Cohesion change & -cohesion change \\
\hline
\end{tabular}




\begin{tabular}{cc}
\hline Level shift & $\begin{array}{c}\text {-phonology to morphology } \\
\text {-syntactic to lexis }\end{array}$ \\
\hline Scheme change & -parallelism to alliteration \\
\hline
\end{tabular}

\section{Parallelism}

In Parallelism in Modern English Prose Sopher (1982) classifies parallelism into eight levels known as formal patterns. These were syntactical, positional, lexical, morphological, phonological, metrical, numerical and multiple levels. The following examples demonstrated by Sopher (1982) cover with these levels of parallelism:

1. Syntactic parallelism

Nature gave women too much power, the law gives them too little (as cited in Sopher, 1982, p. 37). As we can see syntactic parallelism occurs at the syntactic level; the sentences on both sides of the comma are syntactically equal or parallel.

2. Positional parallelism

Your rage I defy your abilities, since your homer, are not so formidable, and what I hear of your morals inclines me to pay regard not to what you shall say but to what you shall do (as cited in Sopher, 1982, p. 38). Besides, positional parallelism is achieved when thematically related words or word combinations have parallel places in their relevant clause (Sopher, 1982). The parallelism of your rage and your abilities is primarily positional. This may be demonstrated by rewriting the first sentence I defy your rage. Then, the notional connection between your rage and your abilities is considerably weakened your moral is parallel to (and notionally linked with) your rage and your abilities only by virtue of its common syntactic pattern (determiner + noun) and its common lexical item your (Sopher, 1982).

3. Lexical parallelism

Everybody's trying to find a car that will stop smoking. I'm trying to find one that will stop drinking (as cited in Sopher, 1982, p. 39).

4. Morphological parallelism

Where everyone's a somebody, then no one's anybody (as cited in Sopher, 1982, p. 39). "The parallelism is produced by the use of identical suffixes (-one and-body)" (Sopher, 1982).

5. Phonological parallelism

Spare the rod and spoil the child (as cited in Sopher, 1982, p. 37). Parallelism here is produced by alliteration (Sopher, 1982).

6. Metrical parallelism

Miss Pinkerton did not understand French, / she only directed those who did (as cited in Sopher, 1982, p. 40). It is produced by means of correspondence in the prosodic pattern of two or more structures (Sopher, 1982).

7. Numerical parallelism

This land was gift no gift. The firstlings worked for it, fought for it, died for it. They stole, cheated and double crossed for it (as cited in Sopher, 1982, p. 40). This is present when two or more units have an identical number of components (Sopher, 1982). This example is tertiary and is not accidental. It arises out of the writer's conscious or unconscious desire for symmetry (Sopher, 1982). 


\section{Multiple parallelism}

If religion is that which binds men to one another, and irreligion that which sunders, then must I testify that I found the religion of my country in its musical genius, and its irreligion in its churches and drawing rooms (as cited in Sopher, 1982, p. 37). Multiple level parallelisms are present at more than one level. The multiple parallelism above is produced by syntactical and some lexical elements (Sopher, 1982).

The classifications above help the researchers determine and classify any parallelism occurring in both texts in question. Parallelism may not occur at the syntactical level only, but it may occur at different levels as well. By the same token, parallelism in the ST may occur at syntactic level while in the TT it may occur at the phonological level.

\section{Syntactic Strategies}

The current study is guided by the translation strategies suggested by Chesterman (1997) who offers a heuristic approach which works in practice, employs accessible terminology, is flexible and open-ended. Chesterman's (1997) translation strategies consist of three primary groups; syntactic/grammatical, semantic and pragmatic. The researchers, however, chose only the syntactic strategy for the present research (Figure 1). The researchers chose that model because the strategies as suggested by Chesterman (1997) are characterised by their applicability to the English-Arabic analysis and parallel structures lie in parallel syntactic structures which conform to this model to a great extent.

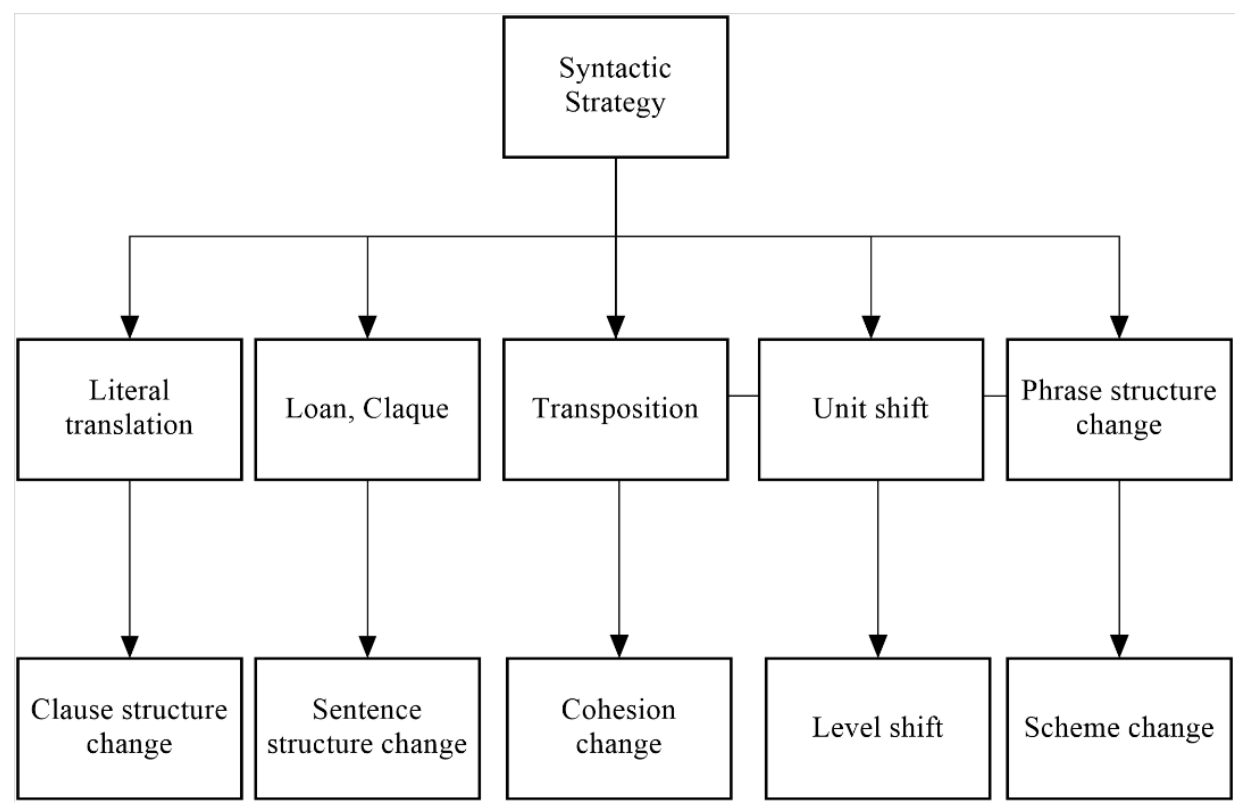

Figure 1. Syntactic strategies of Chesterman (1997) 
According to Chesterman (1997, p. 91), the syntactic strategies "may be thought of as involving purely syntactic changes of one kind or another. Larger changes obviously tend to involve smaller ones too."

i. Literal translation is "maximally close to the SL form, but nevertheless grammatical" (p. 94)

ii. Loan/Calque"The strategy covers individual items borrowed or introduced into another language by dint of translation. It is a deliberate choice and not the unconscious influence of an undesired interference.

iii. Transposition: the strategy involves a change in word-class; from noun to verb, adjective to adverb.

iv. Unit shift: Catford's (1995) term; the strategy is about the ST unit being translated to a different unit in the TT. The units can be morphemes, words, phrases, clauses, sentences and paragraphs.

v. Phrase structure change: a strategy or rather a group of strategies comprising a number of changes at phrase level, including number, definiteness and modification in the noun phrase and verb phrase; person, tense and mood.

vi. Clause structure change: a strategy involving clause structure and its constituent phrases. It comprises such constituent orders as subject, verb, complement, adverbial, active vs. passive voice, finite vs. non-finite, transitive vs. intransitive.

vii. Sentence group change: a group of strategies affecting the sentence structure unit as the sentence consists of clause structure units. The strategies are such between main-clause and sub-clause, status changes, sub-clause type changes, etc.

viii. Cohesion change: a strategy which affects intra-textual reference, ellipsis, substitution, pronominalisation and repetition of various types of connectors.

ix. Level shift: shift of phonology, morphology, syntax and lexis.

$x$. Scheme change: the strategy involves the change which the translator incorporates in the translation of rhetorical schemes such as parallelism, repetition, alliteration, metrical rhythm, etc.

\section{Results}

The data collected from the ST and the TT showed that the translator employed several strategies to retain parallelism in Arabic. The strategies were:

1. Literal translation

2. Clause structure change

3. Transposition

\section{Literal Translation}

Literal translation has been the first and foremost translation strategy ever since translation came into existence. The general principle behind literal translation is to 
retain syntactical features in the TT rather than following "free translation" which gives translators the freedom to use different syntactical features in the TT so long as the meaning of the ST is conveyed. for Dickins, Hervey, and Higgins (2002, p. 238), literal translation involves "an SL-oriented, word-for-word, style of translation in which the denotative meaning of all words in the ST is taken as if straight from the dictionary, but the conventions of TL grammar are respected."

\section{Case 1 literal translation}

.... when the Sperm whale was almost wholly unknown in his own proper individuality, and when his oil was only accidentally obtained from the stranded fish.

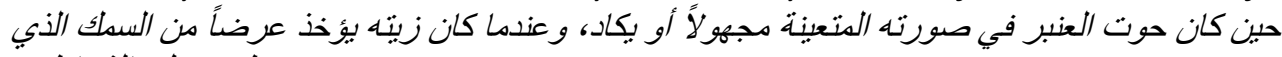
بطرح على الثواطئ،

In Case 1 literal translation, ST parallelism occurs at the syntactic level in the transitive clause SVO; Subject: noun phrase (when the sperm whale, when his oil), Verb: verb phrase (was, was), Object: noun phrase (almost wholly unknown in his own proper individuality, only accidentally obtained from the stranded fish). TT parallelism is achieved at the syntactic level by kaana and its sisters (كان) (كان وأخواتها) VSO; Verb (كان, كان), Subject في محل رفع اسم كان (حوت العنبر , زيته

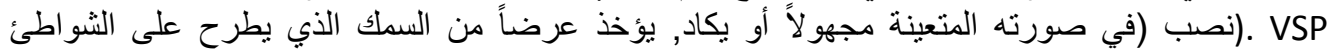
syntactically does not exist in the ST syntactic system. Literal translation is employed here in parallel to what Newmark $(1988$, p. 69) calls "one-to-one translation" which falls under literal translation. According to Newmark (1988), "in one-to-one translation, a broader form of translation, each SL word has a corresponding TL word, but their primary (isolated) meanings may differ" (p. 69). However, in Case 1 above, the TT meaning corresponds to the ST meaning. There is only one difference at the syntactic level and the translator retains most of the syntactic structure of the ST (SVO to VSO). The translator keeps the parallel structure while avoiding repeating the first lexical item 'when'. In this case, he uses synonymy (حين,عندما) at the beginning of the sentence (Abdul-Raof, 2001). The Arabic language has an advantage of the verb "kaana" whose repetition compensates for the loss of ST parallelism at the syntactic level. The repetition of "Kaana" indicates the occurrence of parallelism in Arabic.

\section{Case 2 literal translation}

Their hands met; their eyes fastened; Starbuck's tears the glue.

وتلاقت بي/ها ، والتحمت عيونها وكانت دموع استاربك هي الغر اء الذي دبّقها معاً

In Case 2 literal translation, the position of both Arabic pronouns helps create parallelism at the morphological level. The translator follows literal translation to find parallelism and retain it in the ST. By doing so, he is able to achieve more than one level; subject noun phrase (their hands, their eyes), and verb (met, fastened) and TT VS: verb + subject (التحمت ,تلاقت) and (عيونها ,يداهما). ST parallelism occurs in a complete clause. The structure of subject + verb could not meet more than one level as it does not have similar grammatical typology to Arabic. According to Ghazala (1995), "this method of translation means to translate each SL word or phrase into 
identical word or phrase in the TL, with the same number, grammatical class and type of language" (p. 6).The translator only repeats the syntactic order to achieve the syntactic level of parallelism. However, parallelism in the Arabic language is indicated through a suffix pronoun. The suffix pronoun builds the rhyme in two sentences which, in turn, build morphological parallelism. According to Shunnaq (1993), "the nisba suffix creates a morphological repetition. This type of repetition is numerous and familiar in our texts" (p. 97).

\section{Case 3 literal translation}

Skies the most effulgent but basket the deadliest thunders و السماء أنثد شيء إثراقاً إلا أنها تحتقب أنثد الصواعق فتكاً

In Case 3 literal translation, parallelism does not occur at the syntactic level but at the phonological level. ST Parallelism occurs at the syntactic level in a noun phrase; head (skies, basket), and post-modification (the most effulgent, the deadliest thunders). TT Parallelism occurs at the phonological level in the accusative case $L$ in (فتكاً , إنشر اقاً).

$$
\begin{aligned}
& \text { ST head + post-modification, head + post-modification } \\
& \text { TT إثر اقاً ..... . . . }
\end{aligned}
$$

The syntactic level may occur in the subject predicate; however, the translator translates the noun (basket) in English into a verb in Arabic (تحتقب). This change is necessary to conform to the Arabic grammar rules. Phonological parallelism can be achieved through rhyme (القافية) according to Shamaileh (2011).

The phonological level is indicated in Arabic by the accusative case in the and أنشر|قاsord So, parallelism is formed on account of the word position in the clause.

\section{Clause Structure Change}

The clause structure change was proposed by Chesterman (1997). According to Chesterman,

under this heading I group changes that have to do with the structure of the clause in terms of its constituent phrases. Various subclasses included constituent order (analysed simply as Subject, Verb, Object, Complement, Adverbial), active vs. passive voice, finite vs. non-finite structure, transitive vs. intransitive. (p. 94)

\section{Case 1 clause structure change}

But they worked rather slow and talked very fast, and seemed in anything but a good humour.

$$
\begin{aligned}
& \text { و هم يأخذون المر افع استعداداً لرفع الحوتين إلا أنهم كانوا بعملون في بطء بيتكلمون في عجلة ومهما قلت فيهر }
\end{aligned}
$$

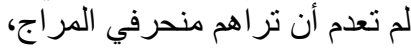

English and Arabic have a similar clause order 'Subject + Verb' as shown in Case 1 clause structure change above; ST parallelism is an intransitive clause SVA; 
subject (they, implied subject), verb (worked, talked) and adjunct (rather slow, very fast) while in TT parallelism, the clause consists of verb and subject (يعملون, يتكلمون), and a circumstantial accusative (في بطء, في عجلة). Furthermore, the ST adjuncts "rather slow" and "very fast" do not comply with VSO which is exclusive to Arabic. Thus, the retention of parallelism only differs in the concept of adjunct and circumstantial accusative. Both of them function as modifiers for the clause that precedes them. Although the translator does not translate the adverb (rather, very), he still retains parallelism in the TT.

\section{Case 2 clause structure change}

To dress in the dark, and eat in the dark, and stumble in darkness to his pallet, this is his usual lot.

وقد كتب على ذلك البحار أن يلبس فى الظلام ويأكل فى الظلام ، وبتعثر في الظلام نحو فر اثشه،

Case 2 clause structure change above shows that parallelism occurs at a similar level. The ST dependent clause; verb (dress, eat, stumble), and adjunct (in the dark, in the dark, in darkness), while there is TT VC in the TT; verb (ويتعبر ,ويأكل يلبس), circumstantial accusative (في الظلام ,في الظلام ,في الظلام). The indefinite subject of the verb is retained through the subjunctive mode. Each verb is marked by at the end of it followed by a prepositional phrase في الظلام. The TT also has lexical parallelism which occurs by dint of the repetition of في الظلام This lexical parallelism occurs when the translator retains the phrase في الظلام as the Arabic vocabulary refers to a single class "noun". In English, "dark" and "darkness" are similar and refer to a noun but "dark" can also be categorised as an adjective. In addition, lexical parallelism occurs by dint of the prepositional phrase في الظلام which is the equivalent of 'in the dark' and the equivalent of "in darkness" in the second clause "stumble in darkness". Although there are two different lexical items in the ST, the translator provides the same lexical items in the TT.

\section{Transposition}

According to Vinay and Darbelnet (1995), "the method called transposition involves replacing one word class with another without changing the meaning of the message" (p. 36). However, cases shown here are about structural change which are mentioned by Chesterman (1997) "normally, this strategy obviously involves structural changes as well" (p. 95). According to Catford (1965), grammatical structural shifts (Catford's term for transposition) and structure shifts can occur at any rank (p. 77). Several transpositions are shown in the cases below. For instance, a noun phrase structure is transposed into a subject predicate structure.

\section{Case 1 transposition}

Doubts of all things earthly, and intuitions of some things heavenly

$$
\text { الشكوك في الأمور الأرضية، والحس في الأمور السماوية. }
$$

Case 1 transposition shows that transposition occurs in translation because of the linguistic differences between the two languages. In Case 1, ST parallelism occurs in the noun phrase (NP) and TT parallelism occurs at the subject predicate (SP) level. ST 
Parallelism occurs at the syntactic level by dint of a noun phrase; Head (doubts, institutions), Preposition (of, of), Post-modifier (all things earthly, some things heavenly). Parallelism is achieved at the syntactic level in the TT by dint of subject predicate; subject (الثكوك, والحس), predicate (في الأمور الأرضية , في الأمور السماوية). Besides, it is also achieved at the phonological level الأرضية and السماوية فية الارضية. According to Al-Jubouri (1984), “...the repetition of content is combined with repetition of form. This is done with the intention of creating a stronger, more rhythmic and more passionate effect" (p. 109). The translator retains the grammatical order by using subject and predicate to maintain the parallel form. The ST has a noun phrase structure, while the TT has a subject and predicate structure.

ST head + post-modifier, head + post-modifier

TT subject + predicate, subject + predicate

\section{Case 2 transposition}

If this ship come to any deadly harm; and come to deadly harm, my soul swears this ship will, if Ahab have his way.

$$
\begin{aligned}
& \text { إذا لقيت هذه السفينة أذى بالغا مديتا. إما أنها ستلقى أذى بالغا مديتاً فان روحي تقسم أن ذللك حادى لا ريب فيه }
\end{aligned}
$$

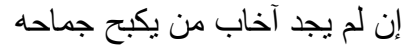

Case 2 transposition shows the transposition from VO to VSO adj. Parallelism occurs in VO which does not include a subject because it is not repeated, while VSO has a subject. The object in the TT is split up into an object and an adjective. ST Parallelism occurs at the syntactic level; verb or phrasal verb (come to, come to), object (any deadly harm, deadly harm). TT Parallelism occurs at the

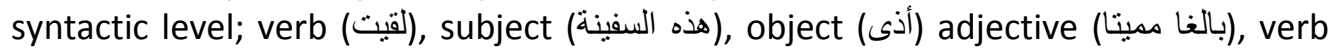
subject (ستلقى), object (أذى) adjective (بالغا مميتا).

$$
\begin{array}{ll}
\text { ST } & \text { Verb + object, } \\
& \text { Verb + object } \\
\text { TT Verb + Subject+ Object+ Adjective, } & \text { Verb + Subject+ Object+ Adjective }
\end{array}
$$

The translator puts the subject after the verb in accordance with VSO in Arabic, unlike the ST SVO. In addition, the translator adds the connector إما أنها connect the second clause ( ستلقى أذى بالغا مميناً) that will make two different clauses. The ST object (any deadly harm) is syntactically placed as object (أذى) and the adjective (بالغا مميت) in the TT describes the subject.

\section{Case 3 transposition}

Its extreme downtown is the battery, where that noble mole is washed by waves, and cooled by breezes, which a few hours previous were out of sight of land.

$$
\begin{aligned}
& \text { و عند أقصاها يقع ذلك السدّ العتيد الذي تغسله الهوجات وتنعشه النسمات، وإذا كنت في الطرف الآخر من }
\end{aligned}
$$

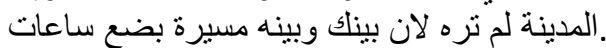

Case 3 transposition shows that the agent in the passive clause is transposed into subject in the TT. Parallelism in the ST occurs at the syntactic level by dint of a verbal clause; Verb + Agent in passive clause: verb phrase (washed by, cooled by) agent (waves, breezes). However, TT parallelism occurs by means of VOS: Verb (تغسل, (تنعش) Object (النسمات, الموجات) Subject). The order is changed from Subject Verb 
Agent into Verb Object Subject VOS. The ST passive clause is Subject + verb +agent: subject (Noble Mole), Verb phrase (is washed by) the agent (waves) takes the position of the object in the TT in which the subject (noble mole) transforms into the pronoun ( $(-)$ attached to verb (تغسلـ). This transposition of the agent is not up to the translator but up to the Arabic syntactic structure. As can be seen, only the structure is changed but passivity is not retained because الموجات and النسمات are the doers in Arabic. Passive voice is used in Arabic only when the doer is unknown, and the noun replacing it is syntactically known as نائب الفاعل 'subject of the passive'.

\section{Conclusion}

The findings of the current study show that the translator of "Moby Dick" did not follow all the syntactic strategies proposed by Chesterman (1997). A close examination of the Arabic translation of "Moby Dick" revealed that the translator followed three strategies only: literal translation, clause structure change and transposition to retain parallelism in the TT. Literal translation was the most common translation strategy followed by the translator because it helped him achieve parallelism in the TT. Clause structure change occurs at clause level. Since English and Arabic belong to two different families, they have different linguistic systems. Because of these linguistic differences, the translator tried to achieve parallelism in the TT by providing clause structures different from those in the ST. Last, the translator used transposition in order to retain parallel structures in the TT. He did so by varying word order in the TT and providing active voice in the TT for passive voice in the ST. Further studies on parallelism can shed light on other syntactic strategies proposed by Chesterman or any other translation theorists and trace such strategies in the translation of another literary work.

\section{References}

Abdul-Raof, H. (2001). Arabic stylistics: A coursebook. Wiesbaden: Harrassowitz.

Al-Jubouri, A. (1984). The role of repetition in Arabic argumentative discourse. In J. Swales, \& H. Mustafa (Eds.), English for specific purposes in the Arab world (pp. 99-111). Birmingham: Language Studies Unit, University of Aston in Birmingham.

Al-Subhi, A. S. (2009). Parallelism in selected children's poems by Eloise Greenfield: A stylistic study. (Unpublished Master Degree). Umm Al-Qura University, Mecca.

An, V. T. (2010). An investigation into syntactic and pragmatic features of parallelism in

English and Vietnamese political speeches. (Unpublished Master Degree). University of Danang, Danang.

Catford, J. C. (1965). A linguistic theory of translation. London: Oxford University Press.

Chesterman, A. (1997). Memes of translation: The spread of ideas in translation theory (Vol. 22). Amsterdam: John Benjamins Publishing. 
de Oliveira Branco, S. (2012). Describing the methodological procedure of a translation studies investigation based on corpora. Domínios de Lingu@gem, 5(3), 95-118.

Dickins, J., Hervey, S., \& Higgins, I. (2002). Thinking Arabic Translation: A course in translation method: Arabic to English. London: Routledge.

Ghazala, H. (1995). Translation as problems and solutions. A textbook for university students and trainee translators (Special ed.). Beirut: Dar El-IIm Lilmalayin.

Mehawesh, M. I. (2013). Grammatical parallelism in the translation of advertising texts with particular reference to English and Arabic. Asian Social Science, 9(10), 254.

Mizher, R. A. (2016). Chesterman's syntactic strategies in translating English passive voice Construction into Arabic. International Journal of Comparative Literature and

Translation Studies, 4(3), 32-43.

Newmark, P. (1988). A textbook of translation. New York: Prentice hall.

Shamaileh, S. F. (2011). The translation of parallelism in political speeches (Doctoral dissertation, Salford: University of Salford).

Shunnaq, A. T. (1993). Patterns of repetition in Arabic forced by morphology with reference to Arabic-English translation. Papers and Studies in Contrastive Linguistics, 28, 89-98.

Sopher, H. (1982). Parallelism in modern English prose;. English Studies, 63, 37-48. doi:10.1080/00138388208598156.

Vinay, J. P., \& Darbelnet, J. (1995). Comparative stylistics of French and English a methodology for translation. Amsterdam: John Benjamins Publishing Company.

Zhao, M. (2012). The art of balance: A corpus-assisted stylistic analysis of Woolfian parallelism in "To the lighthouse". IJES, International Journal of English Studies, 12(2), 39-58. 